\title{
ISOLATION AND IDENTIFICATION OF FUNGAL AGENTS IN PATIENT WITH CORNEAL ULCER IN TERTIARY CARE OPHTHALMIC HOSPITAL
}

\author{
M. R. Vasanthapriyan'1, J. Raja², Ravindren Thyagarajan ${ }^{3}$, B. Kiruthikaa ${ }^{4}$
}

${ }^{1}$ Assistant Professor, Institute of Microbiology, Madurai Medical College, Madurai.

${ }^{2}$ Assistant Professor, Department of Virology, King Institute of Preventive Medicine, Guindy, Chennai.

${ }^{3}$ Professor, Department of Microbiology, Government Kilpauk Medical College, Chennai.

${ }^{4}$ Consultant Cardiothoracic Anaesthetist, Velammal Speciality Hospitals, Madurai.

\section{ABSTRACT}

\section{BACKGROUND}

The cornea is usually kept free from microbial invasion due to the intact epithelium and cleansing effect of the tears. Corneal ulceration is defined as any disruption to the intact epithelium with underlying stromal infiltration and suppuration associa ted with signs of inflammation, the organism either being implanted from without or from the conjunctival flora. Exceptions to the rule are Neisseria gonorrhoeae and Corynebacterium diphtheriae, which are able to invade an intact epithelium. These organisms have the potential to cause microbial keratitis and corneal ulceration, given the appropriate condition and predisposing risk factors. A wide spectrum of microbial organisms like bacteria, virus, fungus and parasite can produce infectious corneal ulcers. The fungal isolates commonly associated with infectious corneal ulceration are Aspergillus species, Penicillium species and Fusarium species. The commonly encountered aetiological agents of fungal corneal ulcers show wide geographical variation. Breakdown of corneal defence mechanism will allow entry of microorganisms to lodge in the corneal stroma. Activation of compliment and release of mycotoxins result in suppurative corneal ulceration.

\section{MATERIALS AND METHODS}

Samples are collected by corneal scraping and examined by KOH mount and direct smear. Further, they were inoculated in SDA for culture. Identification of fungal culture was done by lactophenol cotton blue and slide culture methods.

\section{RESULTS}

A total of 160 patients with infectious corneal ulcer were selected for the study; 97 cases were culture positive (60.6\%). Considering the sex distribution, 61 (64.21\%) males and 36 (55.38\%) female patients showed positive culture. A high prevalence of fungal corneal ulcers was seen among males contributing to $64.21 \%$ of cases. Among the fungal isolates, 58 out of 97 (59.7\%) cases were due to Aspergillus species and the next common agent isolated was Penicillium species (16.49\%) followed by Fusarium species (10.3\%), Curvularia species (6.18\%), Acremonium species (3.09\%) and Candida species (4.12\%).

\section{CONCLUSION}

Infectious fungal corneal ulceration is a sight threatening condition with significant ocular morbidity due to their varied aetiology, unless the aetiological agents are correctly and promptly identified and treatment instituted at the earliest. They can result in permanent damage to the cornea with permanent loss of vision. Precise identification of the causative organisms and timely institution of appropriate fungal therapy based on the prevailing sensitivity pattern of the fungal isolates could save the eye from this preventable cause of blindness.

\section{KEYWORDS}

Corneal Ulcer, Aspergillus, Fungal Culture.

HOW TO CITE THIS ARTICLE: Vasanthapriyan MR, Raja J, Thyagarajan R, et al. Isolation and identification of fungal agents in patient with corneal ulcer in tertiary care ophthalmic hospital. J. Evolution Med. Dent. Sci. 2017;6(26):2178-2181, DOI: $10.14260 /$ Jemds/2017/472

\section{BACKGROUND}

The cornea is usually kept free from microbial invasion due to the intact epithelium and cleansing effect of the tears. Corneal ulceration is defined as any disruption to the intact epithelium with underlying stromal infiltration and suppuration associated with signs of inflammation, the

Financial or Other, Competing Interest: None.

Submission 23-02-2017, Peer Review 19-03-2017,

Acceptance 25-03-2017, Published 30-03-2017.

Corresponding Author:

Dr. M. R. Vasanthapriyan,

Assistant Professor,

Institute of Microbiology,

Madurai Medical College,

Madurai-625020.

E-mail: drvasanth82@gmail.com

DOI: $10.14260 /$ jemds $/ 2017 / 472$ organism either being implanted from without or from conjunctival flora.1,2 Exception to the rule are Neisseria gonorrhoeae and Corynebacterium diphtheriae, which are able to invade an intact epithelium. ${ }^{3}$

\section{The Possible Reasons for the Corneal Ulceration are,}

a. Trauma.

b. Infection, which again may be an organism or may be an extension of the disease process from other ocular tissue.

c. Allergic conjunctivitis.

d. Autoimmune disorders.

Conditions like trauma, steroid therapy and immunosuppressive states like Diabetes mellitus render the cornea susceptible to bacterial, fungal or parasitic infections. 4 
Any organism has the potential to cause microbial keratitis and corneal ulceration, given the appropriate condition and predisposing risk factors. A wide spectrum of microbial organisms like bacteria, virus, fungus and parasite can produce infectious corneal ulcers. The fungal isolates commonly associated with infectious corneal ulceration are Aspergillus species, Penicillium species and Fusarium species. The commonly encountered aetiological agent of fungal corneal ulcers show wide geographical variation. ${ }^{5}$

Breakdown of corneal defence mechanism will allow entry of microorganisms to lodge in the corneal stroma. Activation of compliment and release of mycotoxins result in suppurative corneal ulceration.

\section{MATERIALS AND METHODS}

The study was conducted to know the spectrum and aetiopathogenesis of fungal organisms causing keratitis and to evaluate by culture technique the isolated fungi causing corneal ulcer.

The study group comprised of 160 patients attending the cornea clinic at Govt. Regional Institute of Ophthalmic Hospital, Chennai during the period from June 2009 to May 2010.

Specimens taken from patients of corneal ulcer and follow up patients with corneal ulcer. Informed consent obtained from the patients and data collected as per proforma. Corneal scrapings were collected for investigations. This study is approved by Institute Ethical Committee, Govt. Kilpauk Medical College, Chennai.

1. Patient was made to lie down comfortably on a couch.

2. The affected eye was cleaned with sterile saline using sterile swabs.

3. Sterile 2\% Xylocaine (Manufacturer: ASTRA ZENECA, Contains Lidocaine $2 \%$ ) was applied to the eye taking care not to apply too much of it as it may inhibit the growth of the organism.

4. No. 15 bard Parker blades were used to scrape the ulcer. A new sterile blade was used for each patient.

5. Materials obtained from leading edge and base of each ulcer.

\section{Scrapings were Taken and Processed as follows-}

a. Specimen was applied to two sterile microscopic slides for $10 \% \mathrm{KOH}$ (HiMedia) mount and Gram staining (Gram Stain Kit - HiMedia).

b. Specimens were inoculated into two Sabouraud's dextrose agar (Emmons modification) (HiMedia) slants with antibiotics (Gentamicin- HiMedia) without Cycloheximide (HiMedia).

c. Specimen was streaked in a " $\mathrm{C}$ " shaped manner on a Sabouraud's dextrose agar plate.

d. Specimen inoculated in Brain Heart Infusion Broth with Gentamicin.

e. All the reagents and Media used in the study obtained from HiMedia Laboratories, Mumbai.

\section{Specimen Processing}

1. Potassium Hydroxide Mount.

2. Direct Smear.

3. Culture Method (Sabouraud Dextrose Agar).
4. Lactophenol Cotton Blue Stain

5. Riddle's Slide Culture Method.

\section{RESULTS}

\begin{tabular}{|c|c|c|}
\hline $\begin{array}{c}\text { Total No. of } \\
\text { Samples } \\
\text { Collected }\end{array}$ & $\begin{array}{c}\text { No. of Culture } \\
\text { Positive Samples }\end{array}$ & $\begin{array}{c}\text { Percentage of } \\
\text { Culture Positivity }\end{array}$ \\
\hline 160 & 97 & $60.6 \%$ \\
\hline \multicolumn{3}{|c|}{ Table 1. Culture Results } \\
\hline
\end{tabular}

A total of 160 patients with infectious corneal ulcer were selected for the study; 97 cases were culture positive (60.6\%).

\begin{tabular}{|c|c|c|c|c|}
\hline \multirow{2}{*}{$\begin{array}{c}\text { Age } \\
\text { (Years) }\end{array}$} & \multirow{2}{*}{$\begin{array}{c}\text { Total No. } \\
\text { of Cases }\end{array}$} & \multicolumn{2}{|c|}{$\begin{array}{c}\text { No. of Culture } \\
\text { Positives }\end{array}$} & \begin{tabular}{c} 
Percentage of \\
Cases on Total \\
\cline { 3 - 5 }
\end{tabular} \\
\cline { 3 - 5 } & Males & Females & Culture Positive \\
\hline$<10$ & - & - & - & - \\
\hline $11-20$ & 6 & 2 & 1 & $3.0 \%$ \\
\hline $21-30$ & 17 & 4 & 2 & $6.1 \%$ \\
\hline $31-40$ & 26 & 10 & 4 & $14.4 \%$ \\
\hline $41-50$ & 43 & 16 & 10 & $26.8 \%$ \\
\hline $51-60$ & 50 & 24 & 16 & $41.2 \%$ \\
\hline$>60$ & 18 & 5 & 3 & $8.2 \%$ \\
\hline \multicolumn{5}{|c}{ Table 2. Age Distribution } \\
\hline
\end{tabular}

The age and sex distribution of infectious corneal ulcer was analysed; 95 males and 65 females among these patients were studied; $88.7 \%$ (142/160) cases were found to be in age group between 10 - 60 years and $31.25 \%$ (50/160) of cases were in the age group of 51 - 60 years. Extremes of the age group showed low prevalence.

\begin{tabular}{|c|c|c|c|c|}
\hline Nature of Trauma & Male & Female & Total & $\mathbf{\%}$ \\
\hline Vegetative matter & 11 & 5 & 16 & $40 \%$ \\
\hline Dust & 4 & 2 & 6 & $15 \%$ \\
\hline Insect bite & 5 & 2 & 7 & $17.5 \%$ \\
\hline Stone & 2 & 1 & 3 & $7.5 \%$ \\
\hline Iron particle & 1 & - & 1 & $2.5 \%$ \\
\hline Thermal injury & 2 & - & 2 & $5 \%$ \\
\hline Cow's tail & 2 & 1 & 3 & $7.5 \%$ \\
\hline Iatrogenic trauma & 1 & 1 & 2 & $5 \%$ \\
\hline Total (Trauma Cases) & $\mathbf{2 8}$ & $\mathbf{1 2}$ & $\mathbf{4 0}$ & $\mathbf{1 0 0} \%$ \\
\hline \multicolumn{5}{|c|}{ Table 3. Risk Factors } \\
\hline
\end{tabular}

The urban and rural distribution of cases showed higher prevalence of fungal corneal ulcer in rural population accounting for $68.2 \%$. Numerous predisposing factors have been implicated in the development of infectious corneal ulcer, of which trauma alone contributed to $41.23 \%$ of the cases. Steroid administration, post-ocular surgery, native medicine installation account for $23.71 \%$ cases among nontraumatic origin of infectious fungal corneal ulcer. 


\begin{tabular}{|c|c|c|c|}
\hline Non-Traumatic Origin & Male & Female & $\%$ \\
\hline $\begin{array}{c}\text { H/O Steroid intake } \\
\text { (Topical \& Inhalational) }\end{array}$ & 4 & 2 & $10.5 \%$ \\
\hline $\begin{array}{l}\text { H/O prior antifungal use } \\
\text { followup cases }\end{array}$ & 7 & 3 & $17.54 \%$ \\
\hline $\begin{array}{c}\text { Postoperative } \\
\text { (cataract, keratoplasty) }\end{array}$ & 2 & 1 & $5.2 \%$ \\
\hline Leprosy & 1 & - & $1.7 \%$ \\
\hline Bell's palsy & 1 & - & $1.7 \%$ \\
\hline $\begin{array}{l}\text { Native medicine } \\
\text { installation }\end{array}$ & - & 2 & $3.5 \%$ \\
\hline \multicolumn{4}{|c|}{ Table 4. Risk Factors and Sex Distribution } \\
\hline
\end{tabular}

In analysing the contribution of different trauma lesions in fungal corneal ulcer, trauma with vegetative matter like paddy, leaf and wood were implicated in $37.5 \%$ of cases.

\begin{tabular}{|c|c|c|c|c|}
\hline \multirow{2}{*}{ Fungal Agent } & \multirow{2}{*}{$\begin{array}{c}\text { Total } \\
\text { Isolates }\end{array}$} & \multicolumn{2}{|}{ No. of Isolates } & \multirow{2}{*}{$\%$} \\
\cline { 3 - 5 } & & Male & Female & \\
\hline Aspergillus & 27 & 18 & 9 & $27.83 \%$ \\
\hline Aspergillus flavus & 18 & 11 & 7 & $18.55 \%$ \\
\hline Penicillium species & 16 & 9 & 7 & $16.49 \%$ \\
\hline Aspergillus niger & 13 & 8 & 5 & $13.4 \%$ \\
\hline Fusarium species & 10 & 7 & 3 & $10.3 \%$ \\
\hline Curvularia species & 6 & 3 & 3 & $6.18 \%$ \\
\hline Acremonium species & 3 & 2 & 1 & $3.09 \%$ \\
\hline Candida albicans & 4 & 3 & 1 & $4.12 \%$ \\
\hline \multicolumn{7}{|c|}{ Table 5. Prevalence of Fungal Isolates } \\
\hline
\end{tabular}

Among the fungal isolates, 58 out of 97 (59.7\%) cases were due to Aspergillus species, and next common agent isolated was Penicillium species (16.49\%) followed by Fusarium species (10.3\%), Curvularia species (6.18\%), Acremonium species (3.09\%) and Candida species (4.12\%).

\begin{tabular}{|c|c|c|c|}
\hline Gender & $\begin{array}{c}\text { Total No. of } \\
\text { Specimens }\end{array}$ & $\begin{array}{c}\mathbf{1 0 \%} \text { KOH } \\
\text { Positivity }\end{array}$ & $\begin{array}{c}\text { Gram Stain } \\
\text { Positivity }\end{array}$ \\
\hline Male & 95 & 62 & 2 \\
\hline Female & 65 & 34 & - \\
\hline \multicolumn{3}{|c|}{ Table 6. Microscopic Evaluation } \\
\hline
\end{tabular}

$10 \% \mathrm{KOH}$ mount preparation used as a screening test for rapid diagnosis of fungal corneal ulcer showed $96.9 \%$ sensitivity and $96.8 \%$ specificity. Out of the 96 samples showing the presence of fungal elements in $\mathrm{KOH}$ mount 2 were negative for culture. Of the 64 samples, which did not show the presence of fungal elements in $\mathrm{KOH}$ mount 3 gave a positive culture report.

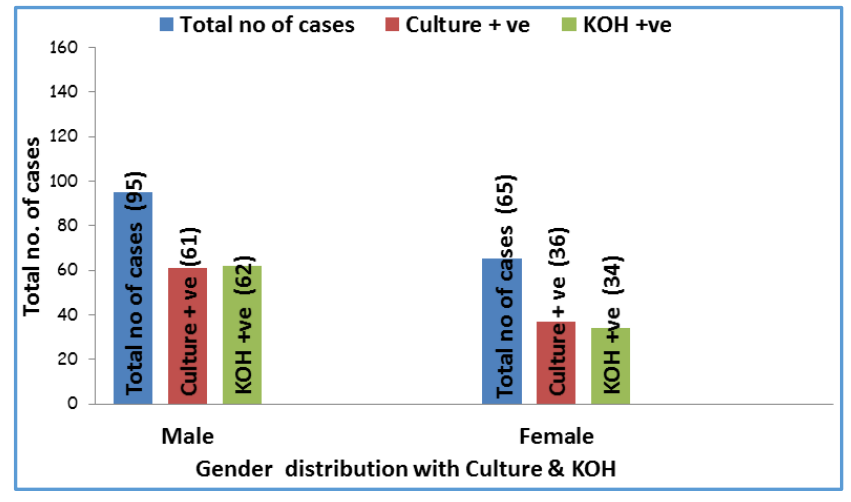

Figure 1. Gender Distribution with Culture and КОH

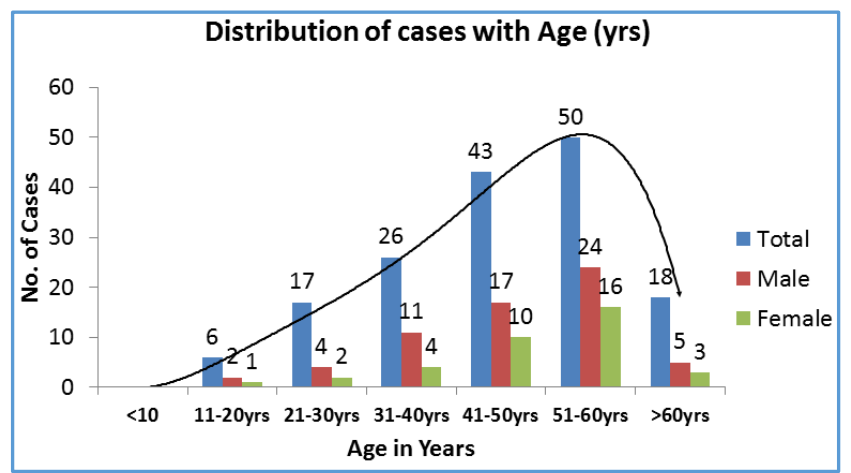

Figure 2. Distribution of Cases with Age (Years)

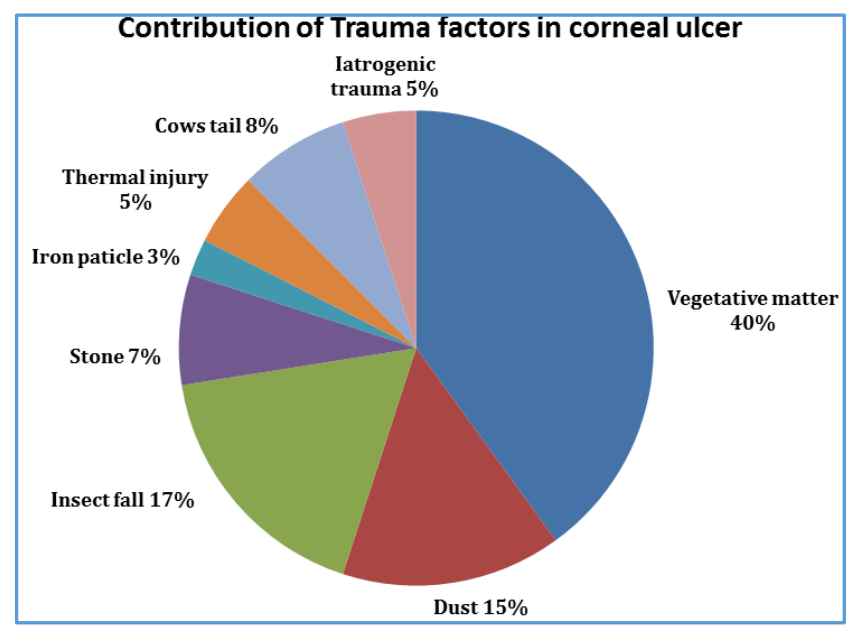

Figure 3. Contribution of Trauma Factors in Corneal Ulcer

\section{Gender Distribution}

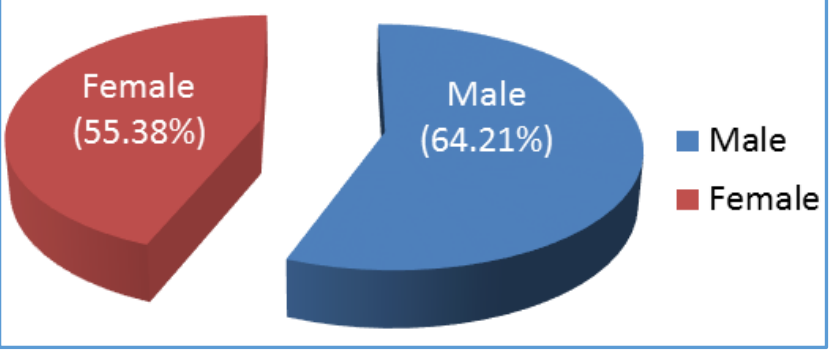

Figure 4. Gender Distribution 


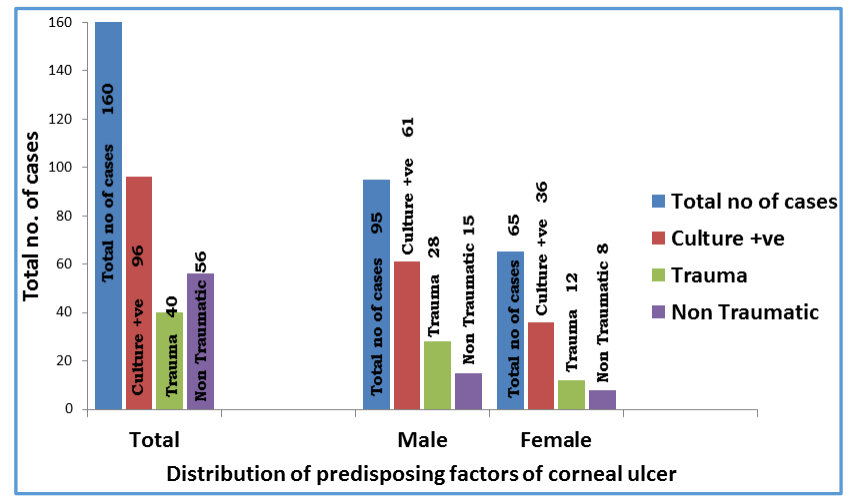

Figure 5. Distribution of Predisposing Factors of Corneal Ulcer

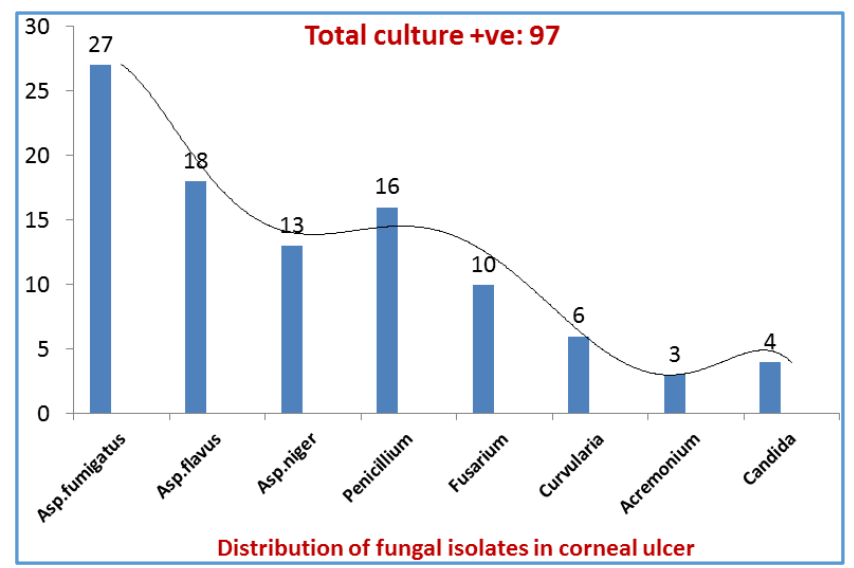

Figure 6. Distribution of Fungal Isolates in Corneal Ulcer

\section{DISCUSSION}

Infectious fungal corneal ulceration is a sight threatening condition with significant ocular morbidity due to their varied aetiology unless the aetiological agents are correctly and promptly identified and treatment is instituted at the earliest, they can result in permanent damage to the cornea with the permanent loss of vision.

Bharathi M J and Ramakrishnan R in 2002 studied the influence of risk factors, climate and geographical variation of corneal ulcer in South India (Tirunelveli) and concluded that vegetative matter is the main risk factor for corneal ulcer and also noted the prevalence is more in male gender.

The specimens for processing collections from the ulcers was taken by scraping gave better results. The present study showed the following results: Out of 160 corneal ulcers studied in detail, 97 cases showed culture positivity which accounted for $60.6 \%$. This was similar to the study of Geetha $\mathrm{K} \mathrm{V}$ et al in 2002 , which revealed $78 \%$ culture positivity. ${ }^{6}$ Bharathi M J et al in 2002 and Khanal B et al in 2005 have reported $70 \%$ and $67.8 \%$ culture positivity in their studies respectively.7,8

The wide variation seen among the reports on the spectrum of fungi causing corneal ulceration could be due to factors such as environment, habits and occupation of individuals, the season during which the studies were conducted, the nature of the predisposing factors, the use of antimicrobials/steroids and native medications to treat the ocular infections and the duration of the lesion.
The rural and urban distribution of corneal ulcer patients in this study revealed highest prevalence of infected corneal ulcers $(65.4 \%)$ in people living in rural areas. This was similar to the study of Basak Samar K et al 2005, in which $78.5 \%$ of the patients were from rural areas. ${ }^{9}$

Among the fungal isolates in this study, 58 (59.7\%) were Aspergillus spp. followed by Penicillium spp. 16 (16.49\%) and Fusarium spp. 10 (10.3\%) and the remaining 13 (13.4\%) isolates were Curvularia spp., Acremonium spp. and Candida spp. It is evident from our study that Aspergillus spp. was by far the commonest filamentous fungi causing corneal ulcer.

The dominant role of Aspergillus species in corneal ulcer has been reported in the studies of Basak Samar K et al in 2005 and Khanal B et al in 2005.8,9 In their studies, the commonest pathogen was Aspergillus species followed by Fusarium species. Zimmerman E. L. et al reported Aspergillus was the commonest isolates in corneal ulcer. This similarity due to climatic and natural environmental survival of the fungal pathogen.

\section{CONCLUSION}

Precise identification of the causative organisms and timely institution of appropriate fungal therapy based on the prevailing sensitivity pattern of the fungal isolates could save the eye from this preventable cause of blindness.

Mass media education and audio visual presentations to create public awareness should be carried out regarding "vision and vulnerability to infection."

\section{REFERENCES}

[1] Bharathi MJ, Ramakrishnan R, Vasu S, et al. Epidemiology of bacterial keratitis in a referral center in South India. IJMM 2003;21(4):239-45.

[2] Srinivasan M. Fungal keratitis. Curr Opin Ophthalmol 2004;15(4):321-7.

[3] Ravi KV. Basic principles in management of bacterial keratitis. Journal of Kerala State Ophthalmology Society 1992:112-6.

[4] Bennett JE, Dolin R, Blaser MJ. Mandell, Douglas, and Bennett's principles and practice of infectious diseases. $6^{\text {th }}$ edn. Chapter 107. Philadelphia: Elsevier Saunders 2005:1395-406.

[5] Bharathi MJ, Ramakrishna R, Meenakshi R, et al. Microbiological diagnosis of infective keratitis: comparative evaluation of direct microscopy and culture results. Br J Ophthalmol 2006;90(10):1271-6.

[6] Vemuganti GK, Garg P, Gopinathan U, et al. Evaluation of agent and host factors in progression of mycotic keratitis: a histologic and microbiologic study of 167 corneal buttons. Ophthalmology 2002;109(8):153846.

[7] Basak SK, Basak S, Mohantha A, et al. Epidemiological and microbiological diagnosis of suppurative keratitis in Gangetic West Bengal, eastern India. Indian J Ophthamol 2005;53(1):17-22.

[8] Khanal B, Deb M, Panda A, et al. Laboratory diagnosis in ulcerative keratitis. Ophthalmic Res 2005;37(3):123-7.

[9] Zimmerman EL. Mycotic keratitis. Lab Investigations 1962;2:1151. 